\title{
Physical Properties of Ophthalmic Hydrogel Polymer Containing Zinc Oxide Nanoparticles
}

\author{
A-Young Sung ${ }^{1 \dagger}$ and Tae-Hun Kim²
}

\begin{abstract}
$\mathrm{ZnO}$ nanoparticles and vinyl pyridine were added to the mixture of MMA (methyl methacrylate), HEMA (2-hydroxy ethyl methacrylate) and NVP (N-vinylpyrrolidone) in a mould at various concentrations. Cross-linker EGDMA (ethyleneglycoldimethacrylate) and AIBN (azobisisobutyronitrile) initiator were finally added to the mixture and then heated at $80^{\circ} \mathrm{C}$ for $60 \mathrm{~min}$ to prepare high-performance hydrogel ophthalmic lens. The physical properties of the hydrogel ophthalmic material were investigated by measuring the average value of refractive index, water content and optical transmittance. The refractive index of $1.429 \sim 1.450$, water content of $34 \sim 41 \%$, and visible transmittance of $78 \sim 90 \%$ were obtained. The material is possibly used to manufacture UV-block hydrogel contact lens.
\end{abstract}

Keywords: Optical Transmittance, Water Content, ZnO Nanoparticles

\section{Introduction}

Various materials including metals and metallic oxides and other functional materials such as $\mathrm{Si}, \mathrm{Ge}$ are utilized as the form of nanoparticles, nanowires or nanotubes. Since nanostructured metal with antibiotic characteristics can be used for industrial and medical applications, studies are more actively conducted on these materials ${ }^{[1-3]}$. In particular, in the case of ophthalmologic materials, physiological characteristics are very important because such materials have to come in direct contact with the cornea of our eyes. The eye is composed of many neurons and various types of fibers, and is an organ that is easily exposed to bacteria under high humidity and proper temperature. Hart et al. reported that $35 \%$ of soft contact lenses worn by people are contaminated with bacteria, E. coli, and fungi ${ }^{[4]}$. Pseudomonas aeruginosa and staphylococci are the most common bacterial pathogens related to the eye that can cause fungal corneal ulcer, pseudomonas corneal ulcer, acute catarrhal conjunctivitis, and chronic bacterial con-

${ }^{1}$ Department of Ophthalmic Optics, Sehan University, Jeonnam, 526702 , Korea

${ }^{2}$ Department of Visual Optics, Baekseok University, Chonnan, 330-704, Korea

${ }^{\dagger}$ Corresponding author : say@sehan.ac.kr

(Received : January 2, 2013, Revised : June 20, 2013,

Accepted : June 24, 2013) junctivitis $^{[5-7]}$. Meanwhile, not only bacterial infections, but also UV is an important cause of ophthalmologic disorders which can cause damage to the cornea, retina and lens, and leads to cataract and photic maculopathy ${ }^{[8,9]}$. Therefore, in order to block UV, benzophenones are being used in contact lens as a UV absorbent. Although various materials for blocking UV were reported, there is still a lack of studies on nanostructure materials that can be used in contact lens. $\mathrm{ZnO}$ nanoparticles have a broad band gap energy and has luminous characteristics at UV due to its high excitation binding energy. Therefore, this material is used in semiconductors, piezoelectric materials and photoconducting materials ${ }^{[10,11]}$, and is broadly used in display screens, leads of photovoltaic cells, light emitting diode, laser diode and photoelectric devices. Here we report the physical characteristics and protein affinity of a hydrogel contact lens polymer made by adding vinyl pyridine and $\mathrm{ZnO}$ nanoparticles to the mixture of HEMA, MA, NVP, and EGDMA in the presence of AIBN initiator.

\section{Experimental Section}

\subsection{Reagents and Materials}

HEMA (2-hydroxyethyl methacrylate) and AIBN (azobisisobutyronitrile) were purchased from JUNSEI, 
and NVP (N-vinyl pyrrolidone) and EGDMA (ethylene glycol dimethacrylate) were purchased from Acros. $\mathrm{ZnO}$ (nanopowder, $<100 \mathrm{~nm}$ particle size), MMA (methyl methacrylate), 2-vinyl pyridine and 4-vinyl pyridine were purchased from Aldrich.

\subsection{Polymerization of Macromolecule}

HEMA, NVP, MMA and EGDMA were used as basic monomer combination for copolymerization and AIBN was used as the initiator. 2-Vinyl pyridine and 4vinyl pyridine were mixed according to the mixing ratio and stirred for approximately 30 mins to add functionality. In addition, the $\mathrm{ZnO}$ nanoparticles, dispersed for approximately $1 \mathrm{hr}$ in an ultrasonic bench top cleaner (branson 2510), were added to the mixture of monomers. Then the mixture at a mould was thermal polymerized. The produced contact lens was then put in $0.9 \%$ $\mathrm{NaCl}$ normal saline solution for $24 \mathrm{hrs}$ for hydration, and various measurements were carried out. Each sample used in this experiment was named Ref., 2VP-1,
2VP-3, 2VP-5, 2VP-7 and 2VP-10 based on the proportion of 2-vinyl pyridine, and was named 4VP-1, 4VP-3, 4VP-5, 4VP-7 and 4VP-10 based on the proportion of 4-vinyl pyridine. The combinations added with $\mathrm{ZnO}$ were named with $\mathrm{z}$ - as a prefix. A total of 5 samples were produced for all combinations and the average value was calculated of the 5 samples. The mixture ratios of the contact lens samples used in this study are summarized in Table 1.

\subsection{Instruments and Analysis}

The surface analysis of $\mathrm{ZnO}$ nanoparticles dispersed in the macromolecular polymer was conducted using AFM (XE-100, Parks System) and the water content was measured and calculated using the gravimetric method based on the ISO 18369-4:2006 standard. The refractive index was measured based on the ISO 183694:2006 and the average of 3 measurements of the hydrated contact lens was obtained using ABBE refractometer (ATAGO NAR 1T, Japan). Optical transmit-

Table 1. Percent compositions of hydrogel samples

\begin{tabular}{|c|c|c|c|c|c|c|c|}
\hline & HEMA & MMA & NVP & EGDMA & $2 \mathrm{VP}^{+}$ & $4 \mathrm{VP}^{++}$ & $\mathrm{ZnO}^{+++}$ \\
\hline Ref. & 93.90 & 0.94 & 4.69 & 0.47 & - & - & - \\
\hline Ref.z & 93.90 & 0.94 & 4.69 & 0.47 & - & - & 0.1 \\
\hline 2VP-1 & 93.02 & 0.93 & 4.65 & 0.47 & 0.93 & - & - \\
\hline $2 \mathrm{VP}-3$ & 91.32 & 0.91 & 4.57 & 0.46 & 2.74 & - & - \\
\hline 2VP-5 & 89.69 & 0.90 & 4.48 & 0.45 & 4.48 & - & - \\
\hline 2VP-7 & 88.11 & 0.88 & 4.41 & 0.44 & 6.17 & - & - \\
\hline 2VP-10 & 85.84 & 0.86 & 4.29 & 0.43 & 8.58 & - & - \\
\hline 4VP-1 & 93.02 & 0.93 & 4.65 & 0.47 & - & 0.93 & - \\
\hline 4VP-3 & 91.32 & 0.91 & 4.57 & 0.46 & - & 2.74 & - \\
\hline 4VP-5 & 89.69 & 0.90 & 4.48 & 0.45 & - & 4.48 & - \\
\hline 4VP-7 & 88.11 & 0.88 & 4.41 & 0.44 & - & 6.17 & - \\
\hline 4VP-10 & 85.84 & 0.86 & 4.29 & 0.43 & - & 8.58 & - \\
\hline 2VPz-1 & 93.02 & 0.93 & 4.65 & 0.47 & 0.93 & - & 0.1 \\
\hline $2 \mathrm{VPz}-3$ & 91.32 & 0.91 & 4.57 & 0.46 & 2.74 & - & 0.1 \\
\hline $2 \mathrm{VPz}-5$ & 89.69 & 0.90 & 4.48 & 0.45 & 4.48 & - & 0.1 \\
\hline 2VPz-7 & 88.11 & 0.88 & 4.41 & 0.44 & 6.17 & - & 0.1 \\
\hline 2VPz-10 & 85.84 & 0.86 & 4.29 & 0.43 & 8.58 & - & 0.1 \\
\hline 4VPz-1 & 93.02 & 0.93 & 4.65 & 0.47 & - & 0.93 & 0.1 \\
\hline $4 \mathrm{VPz}-3$ & 91.32 & 0.91 & 4.57 & 0.46 & - & 2.74 & 0.1 \\
\hline $4 \mathrm{VPz}-5$ & 89.69 & 0.90 & 4.48 & 0.45 & - & 4.48 & 0.1 \\
\hline 4VPz-7 & 88.11 & 0.88 & 4.41 & 0.44 & - & 6.17 & 0.1 \\
\hline $4 \mathrm{VPz}-10$ & 85.84 & 0.86 & 4.29 & 0.43 & - & 8.58 & 0.1 \\
\hline
\end{tabular}

$2 \mathrm{VP}^{+}$: 2-vinyl pyridine, $4 \mathrm{VP}^{++}$: 4-vinyl pyridine, $\mathrm{ZnO}^{+++}$: zinc oxide nanoparticles 
tance was measured for UV-B, UV-A and visible light using spectral transmittance meter (TOPCON TM-2, Japan) and was recorded as percentage values.

\section{Results and Discussion}

\subsection{Polymerization and Analysis of Macromolecule}

The hydrogel contact lens was prepared by the addition of 2-vinyl pyridine and 4-vinyl pyridine to the general monomer mixture with the given ratio in Table 1. The hydrogel lens generally exhibit colorless, transparent and hydrophilic characteristics. The combination containing $\mathrm{ZnO}$ nanoparticles produced light white and transparent contact lens. The contact lenses hydrated in standard normal saline solution for $24 \mathrm{hrs}$ generally exhibited characteristics of flexibility and softness. AFM images are shown in Fig. 1.

\subsection{Water Content and Refractive Index Mea-} surement

The measurement of the water content of the hydrophilic contact lens showed that the average water content for Ref., which does not contain 2-vinyl pyridine, 4-vinyl pyridine and $\mathrm{ZnO}$ nanoparticles, was $39.32 \%$ which is similar to the value of general hydrogel contact lens. The average water content of the 2VP combination with 2-vinyl pyridine was $39.26 \%$ for $2 \mathrm{VP}-1,38.12 \%$ for $2 \mathrm{VP}-3,36.15 \%$ for $2 \mathrm{VP}-5,35.07 \%$

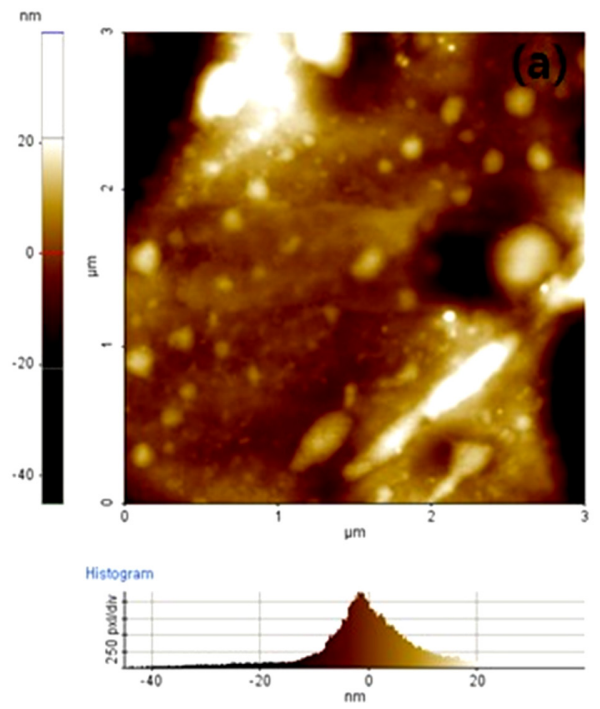

for $2 \mathrm{VP}-7$ and $32.99 \%$ for $2 \mathrm{VP}-10$, respectively. In overall, the measurements showed that the water content decreased as the ratio of 2-vinyl pyridine increased, but a abrupt decrease was not observed. The average water content of the 4VP combination with 4-vinyl pyridine was $38.04 \%$ for $4 \mathrm{VP}-1,37.03 \%$ for $4 \mathrm{VP}-3$, $34.85 \%$ for $4 \mathrm{VP}-5,33.70 \%$ for $4 \mathrm{VP}-7$ and $32.44 \%$ for 4VP-10, respectively. For this combination, the water content decreases as the ratio of 4-vinyl pyridine increases, and the water content was slightly lower overall than that of the 2VP combination. No change in water content with varying the amount of $\mathrm{ZnO}$ nanoparticles was observed in combinations with $\mathrm{ZnO}$ nanoparticles. The water content is similar to that of the sample which does not contain $\mathrm{ZnO}$ nanoparticles, indicating that the addition of $\mathrm{ZnO}$ nanoparticles did not affect the water content of the hydrogels. The figure comparing the water content of the combinations $2 \mathrm{VP}$ and $4 \mathrm{VPz}$ are shown in Fig. 2.

The refractive index is inversely proportional to water content, and a dramatic increase or decrease in refractive index was not observed. The average refractive index of Ref., which does not contain 2-vinyl pyridine, 4-vinyl pyridine and $\mathrm{ZnO}$ nanoparticles, was 1.4333 which is similar to the value of general hydrogel contact lens. The average refractive index of the 2VP combination was 1.4370 for 2VP-1, 1.4423 for 2VP-3, 1.4490 for 2VP-5, 1.4510 for 2VP-7 and 1.4567 for 2VP-10.

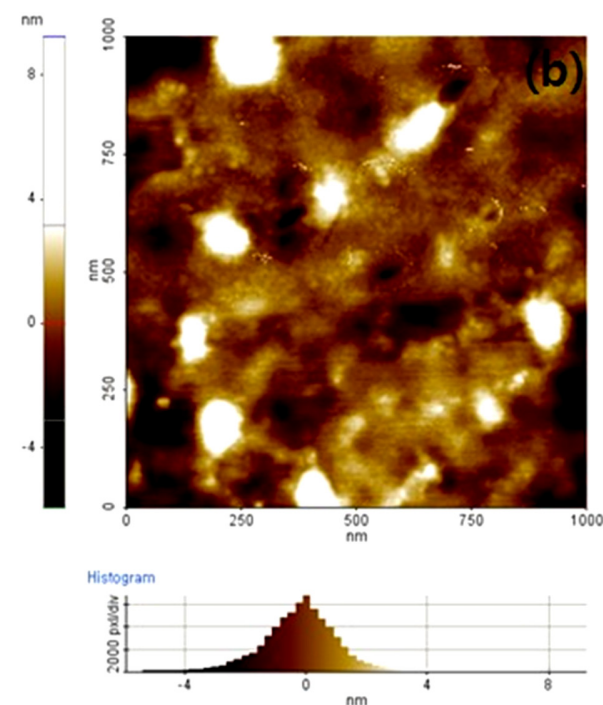

Fig. 1. Surface analysis of hydrogel polymer by AFM. (a) scan size: $3000 \times 3000 \mathrm{~nm}$, (b) scan size: $1000 \times 1000 \mathrm{~nm}$ 


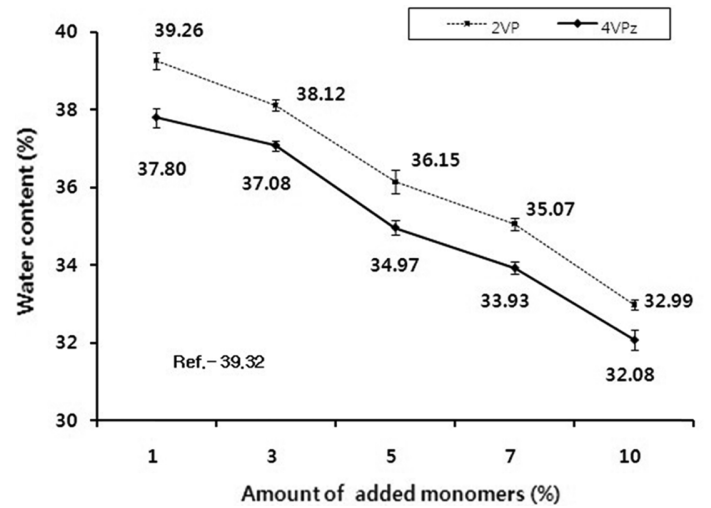

Fig. 2. Effect of added monomers on water content

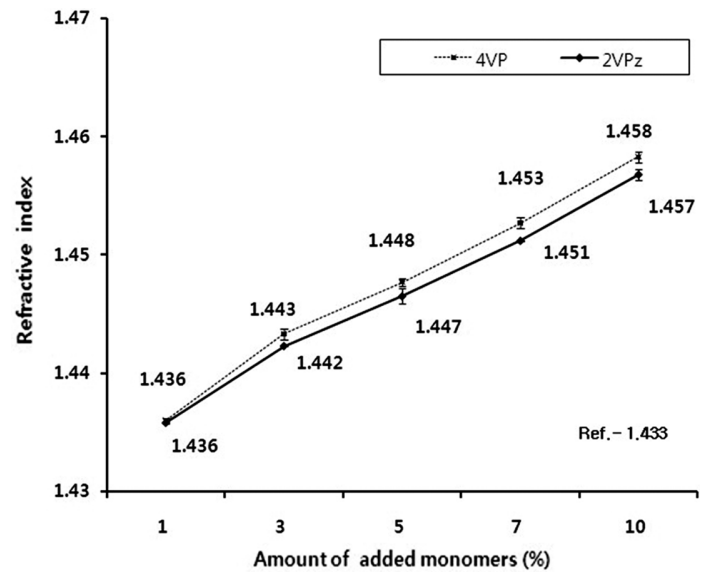

Fig. 3. Effect of added monomers on refractive index

The average refractive index for the 4VP combination was 1.4360 for $4 \mathrm{VP}-1,1.4433$ for $4 \mathrm{VP}-4,1.4477$ for $4 \mathrm{VP}-5,1.4527$ for $4 \mathrm{VP}-7$ and 1.4583 for $4 \mathrm{VP}-10$. No change was observed in refractive index with varying the amount of added $\mathrm{ZnO}$ nanoparticles in each combination and the difference in refractive index of each combination was below 0.002 , indicating that the addition of $\mathrm{ZnO}$ nanoparticles does not affect refractive index. The figure comparing the refractive index of the $2 \mathrm{VPz}$ combination and the $4 \mathrm{VP}$ combination is shown in Fig. 3.

\subsection{Optical Transmittance}

Measurements of the optical transmittance of each sample showed that the average transmittance in Ref., which does not contain 2-vinyl pyridine, 4-vinyl pyridine and $\mathrm{ZnO}$ nanoparticles, is $90.97 \%$ for visible light,
Table 2. Optical transmittances of samples (2VP and 4VP)

Unit - \%

\begin{tabular}{cccc}
\hline Sample & UV-B & UV-A & Visible \\
\hline Ref. & 84.0 & 88.5 & 90.7 \\
2VP-1 & 82.3 & 86.0 & 90.5 \\
2VP-3 & 79.5 & 82.4 & 90.0 \\
2 VP-5 & 74.5 & 81.0 & 91.0 \\
2VP-7 & 69.0 & 79.4 & 90.3 \\
2VP-10 & 65.5 & 78.7 & 90.5 \\
4 VP-1 & 81.5 & 86.7 & 91.0 \\
4 VP-3 & 80.1 & 86.3 & 90.5 \\
4 VP-5 & 77.5 & 85.5 & 90.7 \\
4 VP-7 & 74.0 & 85.0 & 90.2 \\
4 VP-10 & 71.0 & 84.5 & 91.0 \\
\hline
\end{tabular}

$84.0 \%$ for UV-B and $88.5 \%$ for UV-A. In overall, the optical transmittance was high in all wavelengths and the lenses could not block UV light. The average transmittance in the 2VP combination where 2-vinyl pyridine was added at each ratio was in the range of 90.0 91.0\% for visible light, $65.5 \sim 82.3 \%$ for UV-B and $78.7 \sim 88.5 \%$ for UV-A. Although there were no significant differences observed in the transmittance for visual light for each mixing ratio, the transmittance for UV light decreased slightly as the mixing ratio increased. The average transmittance in the 4VP combination where 4-vinyl pyridine was added at each ratio was in the range of $90.2 \sim 91.0 \%$ for visible light, $71.0 \sim 81.5 \%$ for UV-B and $84.5 \sim 86.7 \%$ for UV-A. Although there were no significant differences in the transmittance for visible light for each mixing ratio, the transmittance for UV light decreased slightly as the mixing ratio increased. However, the decrease was smaller than that with $2 \mathrm{VP}$ and there was no significant change observed for UV-A. The optical transmittances for 2VP and 4VP are summarized in Table 2.

The measurement on the optical transmittance of each combinations where $\mathrm{ZnO}$ nanoparticle was added to $2 \mathrm{VP}$ and 4VP showed that the average transmittance is in the range of $76.0 \sim 82.7 \%$ for visible light, $17.0 \sim$ $24.5 \%$ for UV-B and $19.7 \sim 26.7 \%$ for UV-A. Compared to the 2VP combination, the transmittance for UV light was reduced significantly, indicating that UV light was effectively blocked, and the transmittance for UV light decreased with the increase in the mixing ratio for $2 \mathrm{VP}$. 2VP partially blocked the UV. Meanwhile, the average 
Table 3. Optical transmittances of samples (2VPz, 4VPz)

Unit - \%

\begin{tabular}{cccc}
\hline Sample & UV-B & UV-A & Visible \\
\hline Ref. & 84.0 & 88.5 & 90.7 \\
2 VPz-1 & 24.5 & 26.7 & 82.7 \\
2 VPz-3 & 22.5 & 23.8 & 81.0 \\
2 VPz-5 & 19.7 & 21.0 & 79.4 \\
2 VPz-7 & 18.5 & 20.7 & 77.5 \\
2 VPz-10 & 17.0 & 19.7 & 76.0 \\
$4 V P z-1$ & 22.4 & 26.7 & 81.5 \\
$4 V P z-3$ & 21.5 & 24.5 & 80.7 \\
$4 V P z-5$ & 20.7 & 24.0 & 80.3 \\
$4 V P z-7$ & 19.3 & 23.7 & 79.5 \\
$4 V P z-10$ & 19.0 & 23.7 & 78.3 \\
\hline
\end{tabular}
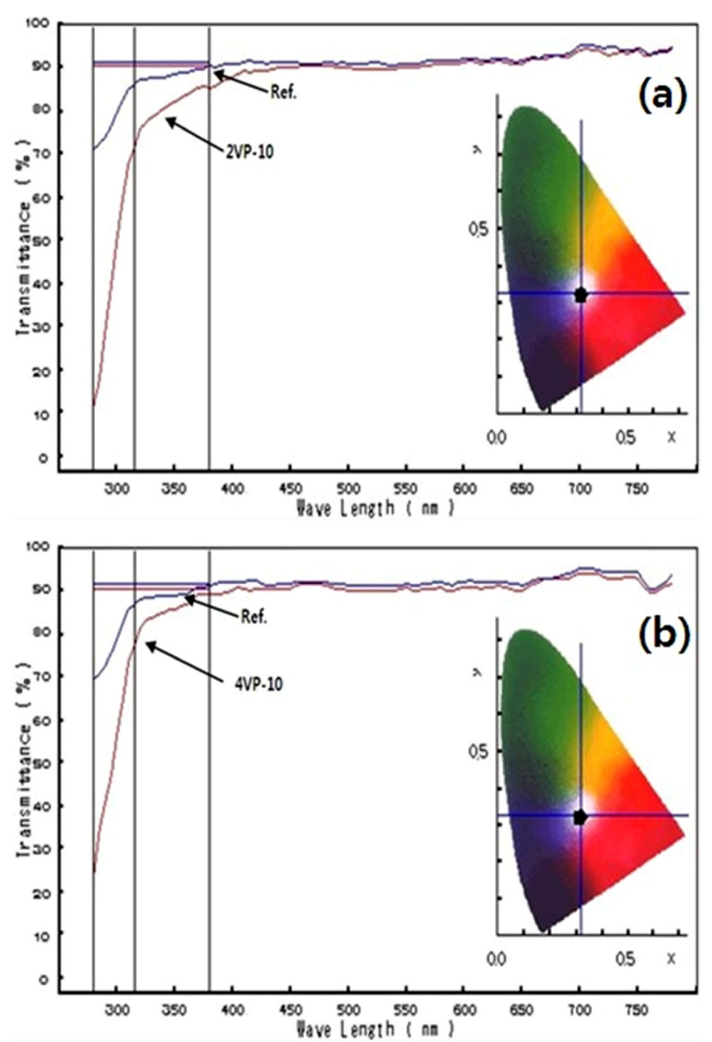

Fig. 4. Optical transmittances of samples: (a) Ref. and 2VP-10, (b) Ref. and 4VP-10

transmittance in $4 \mathrm{VPz}$ was in the range of $78.3 \sim 81.5 \%$ for visual light, $23.7 \sim 26.7 \%$ for UV-B and 19.0 22.4\% for UV-A. Compared to the 4VP combination, the transmittance for UV was reduced significantly, implying that UV was effectively blocked, and the transmittance for UV decreased in link with the increase in the mixing ratio for $4 \mathrm{VP}$. Thus, $4 \mathrm{VP}$ partially blocked the UV. The overall transmittance rate for visible light in the combinations with $\mathrm{ZnO}$ nanoparticles was slightly reduced due to the addition of $\mathrm{ZnO}$ nanoparticles which is not from the loss of transparency but caused largely from the reduced transmittance around the UV wavelength. The optical transmittances for $2 \mathrm{VPz}$ and $2 \mathrm{VPz}$ combination are given in Table 3 . The optical transmittances of 4VP-10 and 4VPz-10 are compared in Fig. 4.

\section{Conclusions}

The use of $\mathrm{ZnO}$ nanoparticle as the UV-blocking material for ophthalmologic devices was investigated by measuring the UV transmittance. The water content decreased in all combinations as the mixing ratio of vinyl pyridine increased while the refractive index increased under the same circumstance. The transmittance for visible light was over $90 \%$ in all combinations, and the transmittance for UV reduced up to a certain level in combinations with 2-vinyl pyridine or 4-vinyl pyridine. The water content and refractive index did not show a significant difference in the combinations with $\mathrm{ZnO}$ nanoparticles, indicating that $\mathrm{ZnO}$ nanoparticles do not affect the water content and refractive index appreciably. The amount of protein deposit showed an increase in proportion to the increase in water content. However, the addition of $\mathrm{ZnO}$ nanoparticles did not change the amount of protein deposit. The transmittance for visible light was over $90 \%$ in all combinations with $\mathrm{ZnO}$ nanoparticle and the transmittance for UV reduced up to a certain level in certain combinations with 2vinyl pyridine or 4-vinyl pyridine. Their transmittance for UV was reduced significantly in combinations with $\mathrm{ZnO}$ nanoparticle showing that $\mathrm{ZnO}$ s effectively block UV. However, $\mathrm{ZnO}$ nanoparticles eluted from the lens over time which resulted in reduced UV-blocking effect. Therefore, 2-vinyl pyridine and 4-vinyl pyridine can be used to control both water content and refractive index. In the case with $\mathrm{ZnO}$ nanoparticle, the material is expected to be able to be used usefully as a material for UV-block hydrogel contact lens for short-term wearing without affecting the water content and refractive index. 


\section{Acknowledgement}

This research was financially supported by Ministry of Knowledge Economy(MKE) and Korea Evaluation Institute of Industrial Technology(KEIT) through the Project of Standard Technology Development

\section{References}

[1] K. H. Ye, T. H. Kim, and A. Y. Sung, "Synthesis of a polymer containing HEMA and gold and silver nanoparticles and its application in contact lenses", J. Kor. Chem. Soc., Vol. 54, pp. 228-233, 2010.

[2] K. H. Ye, T. H. Kim, H. S. Choi, and A. Y. Sung, "Study on the physical properties of polymer containing titanium dioxide and silver nanoparticles", J. Kor. Chem. Soc., Vol. 53, pp. 819-823, 2009.

[3] K. H. Ye and A. Y. Sung, "Study on ophthalmic materials possessing UV-blocking/antimicrobial functions", J. Kor. Chem. Soc., Vol. 53, pp. 460464, 2010.

[4] D. E. Hart, W. Reindel, H. M. Proskin, and M. F. Mowrey-McKee, "Microbial contamination of hydrophilic contact lenses: quantitation and identification of microorganisms associated with contact lenses while on the eye", Optom. Vis. Sci., Vol. 70, pp. 185-191, 1993.
[5] S. K. Lim, S. K. Lee, S. H. Hwang, and H. Y. Kim, "Photocatalytic deposition of silver nanoparticles onto organic/inorganic composite nanofibers", Macromol. Mater. Eng., Vol. 291, pp. 1265-1270, 2006.

[6] J. X. Li, J. Wang, L. R. Shen, Z. J. Xu, P. Li, G. J. Wan, and N. Huang, "The influence of polyethylene terephthalate surfaces modified by silver ion implantation on bacterial adhesion behavior", Surf. Coat. Tech., Vol. 201, pp. 8155-8159, 2007.

[7] M. Rai, A. Yadav, and A. Gade, "Silver nanoparticles as a new generation of antimicrobials", Biotechnol. Adv., Vol. 27, pp. 76-83, 2009.

[8] J. A. Zuclich, "Ultraviolet-induced photochemical damage in ocular tissues", Health Phys., Vol. 56, pp. 671-682, 1989.

[9] A. R. Wegener, "In vivo studies on the effect of UVradiation on the eye lens in animals", Doc. Ophth., Vol. 88, pp. 221-232, 1994.

[10] M. Law, J. Goldberger, and P. Yang, "Semiconducor nanotuves and nanowires", Annu. Rev. Mater. Res., Vol. 34, pp. 83-122, 2004.

[11] Y. I. Alivov, C. Liu, A. Teke, M. A. Reshchikov, S. Doğan, V. Avrutin, S.-J. Cho, and H. H. Morkoç, "A comprehensive review of $\mathrm{ZnO}$ materials and devices”, J. Appl. Phys., Vol. 98, pp. 041301, 2005. 